Research Article

\title{
Diagnostic Accuracy of Bronchoalveolar Lavage Fluid Galactomannan for Invasive Aspergillosis
}

\author{
Xun-Jie Cao,, ${ }^{1,2}$ Ya-Ping Li, ${ }^{1,2,3}$ Li-Min Xie, ${ }^{1,2}$ Hong-Lang Zhang, ${ }^{1,2}$ Yu-Shan Qin,,2 \\ and Xu-Guang Guo iD $1,2,4,5$ \\ ${ }^{1}$ Department of Clinical Laboratory Medicine, The Third Affiliated Hospital of Guangzhou Medical University, \\ Guangzhou 510150, China \\ ${ }^{2}$ Department of Clinical Medicine, The Third Clinical School of Guangzhou Medical University, Guangzhou 511436, China \\ ${ }^{3}$ Department of Clinical Medicine, The Second Clinical School of Guangzhou Medical University, Guangzhou 511436, China \\ ${ }^{4}$ Key Laboratory for Major Obstetric Diseases of Guangdong Province, The Third Affiliated Hospital of Guangzhou \\ Medical University, Guangzhou 510150, China \\ ${ }^{5}$ Key Laboratory of Reproduction and Genetics of Guangdong Higher Education Institutes, The Third Affiliated Hospital of \\ Guangzhou Medical University, Guangzhou 510150, China
}

Correspondence should be addressed to Xu-Guang Guo; gysygxg@gmail.com

Received 26 March 2020; Revised 13 September 2020; Accepted 3 November 2020; Published 1 December 2020

Academic Editor: Federico Carbone

Copyright (C) 2020 Xun-Jie Cao et al. This is an open access article distributed under the Creative Commons Attribution License, which permits unrestricted use, distribution, and reproduction in any medium, provided the original work is properly cited.

\begin{abstract}
Background. The pathogenesis of invasive aspergillosis (IA) is still unknown, but its progression is rapid and mortality rate remains high. Bronchoalveolar lavage fluid (BALF) galactomannan (GM) analysis has been used to diagnose IA. This study is aimed at making an accurate estimate of the whole accuracy of BALF-GM in diagnosing IA. Methods. After a systematic review of the study, a bivariate meta-analysis was used to summarize the specificity (SPE), the sensitivity (SEN), the positive likelihood ratios (PLR), and the negative likelihood ratios (NLR) of BALF-GM in diagnosing IA. The overall test performance was summarized using a layered summary receiver operating characteristic (SROC) curve. Subgroup analysis was performed to explore the heterogeneity between studies. Results. A total of 65 studies that are in line with the inclusion criteria were included. The summary estimates of BALF-GM analysis are divided into four categories. The first is the proven+probable vs. possible+no IA, with an SPE, 0.87 (95\% CI, 0.85-0.98); SEN, 0.81 (95\% CI, 0.76-0.84); PLR, 9.78 (5.78-16.56); and NLR, 0.20 (0.14-0.29). The AUC was 0.94. The BALF-GM test for proven+probable vs. no IA showed SPE, 0.88 (95\% CI, 0.87-0.90); SEN, 0.82 (95\% CI, 0.78-0.85); PLR, 6.56 (4.93-8.75); and NLR, 0.24 (0.17-0.33). The AUC was 0.93. The BALF-GM test for proven+ probable+possible vs. no IA showed SPE, 0.82 (95\% CI, 0.79-0.95); SEN, 0.59 (95\% CI, 0.55-0.63); PLR, 3.60 (2.07-6.25); and NLR, 0.31 (0.15-0.61). The AUC was 0.86. The analyses for others showed SPE, 0.85 (95\% CI, 0.83-0.87); SEN, 0.89 (95\% CI, 0.86-0.91); PLR, 6.91 (4.67-10.22); and NLR, 0.18 (0.13-0.26). The AUC was 0.94. Conclusions. The findings of this BALF-GM test resulted in some impact on the diagnosis of IA. The BALF-GM assay is considered a method for diagnosing IA with high SEN and SPE. However, the patients' underlying diseases may affect the accuracy of diagnosis. When the cutoff is greater than 1 , the sensitivity will be higher.
\end{abstract}

\section{Introduction}

Aspergillus species, as a saprotrophic fungus in soil and decaying vegetation, are widely found throughout the world [1]. Among them, Aspergillus fumigatus is the main cause of invasive aspergillosis [2], which is a severe disseminated fungal disease and causes high morbidity and mortality among severely immunocompromised people [3]. Invasive aspergillosis (IA) occurs not only in patients with long-term neutropenia and with a history of allogeneic hematopoietic cells or solid organ transplants but also in those who use high-dose corticosteroids or genetically severe immune defective patients [4]. The invasive fungal infections in particular are also considered a significant cause of morbidity 
and death in immunocompromised patients [5]. The culture and microscopy still remain the gold standard for diagnosing IA, but the lack of positive cultures in blood or tissues delays the diagnosis of this infection. This requires invasive procedures, but it is difficult to implement in some cases, such as in critically ill patients or those with thrombocytopenia [5, 6]. Therefore, it is necessary to improve the fatally invasive fungal infections caused by delayed diagnosis, and so rapid processing and reporting are regarded essential.

Galactomannan (GM) is a polysaccharide that exists in the Aspergillus cell wall, which proliferates during invasive infections and is subsequently detected in the serum and other bodily fluids [7]. The role of GM might assist in diagnosing IA and has become the focus of clinical research [8]. There have been many studies on the accuracy of bronchoalveolar lavage fluid GM in the diagnosis of IA. Therefore, the 2016 ESCMID-ECMM-ERS guidelines recommended serum and bronchoalveolar lavage fluid (BALF) GM as markers for diagnosing IA [9].

To date, many studies have assessed the accuracy of the BALF-GM test in diagnosing IA. In 2012, a systematic review of 30 clinical studies evaluated patients with IA using the BALF-GM test and concluded that the optimal threshold for the BALF-GM test was 1.0 when the sensitivity (SEN) is higher [10]. Therefore, a more systematic assessment on the accuracy of the BALF-GM test in diagnosing IA through a meta-analysis was conducted in our study.

\section{Methods and Materials}

2.1. Research Identification and Selection. Two investigators (XJ Cao and YP Li) searched the databases such as EMBASE, PubMed, the Cochrane Library, and Web of Science for interrelated articles published till November 9, 2019. The bibliography of the included studies was also screened. The results were then manually searched for a qualifying test. Studies that were in line with the following criteria were included: (1) provided data of two-by-two tables and (2) full-text publications. The studies were excluded if the following criteria were met: (1) insufficient data, such as meeting summaries, (2) studies with less than 10 patients which were excluded in order to avoid selection bias, (3) metaanalysis and systematic reviews, and (4) animal research.

2.2. Quality Assessment and Data Extraction. Two investigators (XJ Cao and YP Li) independently extracted the following information: population, study, diagnostic standard, sample size, and assay characteristics; methodological quality; and data for two-by-two tables and optical density index (ODI). During the evaluation process, if there was a difference between the evaluation results of the two investigators, we shall unify opinions through discussion. A modified quality assessment for diagnostic accuracy study (QUADAS) tool was used to assess the study quality [8].

2.3. Statistical Analysis. To analyze a summary estimate of BALF-GM, a BALF-GM test was constructed to crossclassify into two-by-two tables (proven+probable IA vs. no IA) and two-by-two tables (proven+probable, possible IA vs. no IA). Also, the two-by-two tables (proven+probable IA vs. possible+no IA) and the two-by-two tables (other which included not EORTC/MSG consensus criteria and proven vs. no or colonization and so on) were constructed. Based on the revised EORTC/MSG consensus criteria [11], the patients were divided into four groups according to their IA diagnosis. For studies that reported multiple cutoffs, the cutoff that provided the best performance was used. A binary regression method with $95 \%$ confidence interval (CI) was used as the main outcome indicator to assess the overall specificity (SPE) and sensitivity (SEN), and a layered summary receiver operating characteristic (SROC) curve was constructed [12]. What is more, the pooled SPE and SEN were also used to calculate negative likelihood ratios (NLR) and positive likelihood ratios (PLR) [12].

The statistically significant heterogeneity was assessed using $I^{2}$ statistics and explored potential heterogeneity between studies through subgroup analysis. Subgroup analysis was performed for different cutoffs that are 0.5 to 1 and greater than 1. A funnel plot was constructed to visually check for any potential publication bias [13].

The analyses were performed using Stata statistical software package, version 12.0 (StataCorp LP, College Station, U.S.A.) and Meta-DiSc 1.4.

\section{Results}

3.1. Study Inclusion and Exclusion Criteria and Quality Assessment. Of the 896 identified studies, 65 eligible studies were eventually pooled [14-78]. The flow diagram is shown in supplementary materials (Figure S1). The characteristics of the eligible studies are presented in Table 1. Of these 65 eligible studies, 58 were cohort studies and 7 were casecontrol studies. The bar chart represents the quality assessment according to the improved QUADAS standard (Figure 1).

3.2. Analyses for Proven+Probable vs. No IA. The analyses for proven+probable vs. no IA were included in 23 studies, and 21 studies demonstrated a cutoff value of 0.5 to 1.0 , and one of the two remaining had a cutoff value of 2.89 and another remained unknown. The SPE and SEN were 0.88 (95\% CI, 0.87-0.90) and 0.82 (95\% CI, 0.78-0.85), respectively. The NLR and PLR were 0.24 (95\% CI, 0.17-0.33) and 6.56 (95\% CI, 4.93-8.75), respectively. Diagnostic odds ratio (DOR) was 35.04 (23.75-51.71).

The SROC curve is displayed in Figure 2, representing the relationship between SPE and SEN throughout the study. The area under the SROC curve (AUC) was 0.93, which indicated that the BALF-GM assay has a high diagnostic capability.

The results of subgroup analyses for "proven or probable vs. no IA" are shown in Table 2, Figure S2, and Figure S3. The sensitivity and specificity demonstrated no significant changes. However, the heterogeneity remained significantly lower.

3.3. Analyses for Proven + Probable vs. Possible + No IA. The analyses of proven+probable vs. possible+no IA were 
TABLE 1: Characteristics of 65 studies included in the meta-analysis of diagnosis of IA using BALF-GM.

\begin{tabular}{|c|c|c|c|c|c|c|c|}
\hline Study & Diagnostic standard & $\begin{array}{c}\text { Best } \\
\text { cutoffs }\end{array}$ & $\begin{array}{l}\text { Sample } \\
\text { size }\end{array}$ & $\begin{array}{l}\text { Study } \\
\text { design }\end{array}$ & $\begin{array}{c}\text { Patient } \\
\text { population }\end{array}$ & Mean age & $\begin{array}{c}\text { Male } \\
(\%)\end{array}$ \\
\hline Sehgal 2019 & EORTC/MSG criteria & 2.5 & 127 & $\begin{array}{c}\text { Case } \\
\text { control }\end{array}$ & $\begin{array}{c}\text { Adults with } \\
\text { MTHF }\end{array}$ & 45.2 & 56.5 \\
\hline Liu 2019 & EORTC/MSG criteria & 0.85 & 190 & Cohort & $\begin{array}{l}\text { Adults with } \\
\text { MTHF }\end{array}$ & NA & NA \\
\hline Jenks 2019 & $\begin{array}{l}\text { (1) EORTC/MSG criteria; (2) a slightly } \\
\text { modified version of the clinical algorithm } \\
\text { described by Blot and colleagues }\end{array}$ & 1 & 82 & Cohort & $\begin{array}{c}\text { Nonneutropenic } \\
\text { adults }\end{array}$ & NA & 39.0 \\
\hline Rozaliyani 2019 & EORTC/MSG criteria & 2 & 155 & Cohort & $\begin{array}{l}\text { Adults with } \\
\text { MTHF }\end{array}$ & NA & NA \\
\hline Yu 2019 & EORTC/MSG criteria & 2.94 & 184 & Cohort & $\begin{array}{c}\text { Nonneutropenic } \\
\text { people }\end{array}$ & NA & 0.4 \\
\hline Bellanger 2018 & EORTC/MSG criteria & 0.5 & 597 & Cohort & $\begin{array}{l}\text { Adults with } \\
\text { MTHF }\end{array}$ & NA & NA \\
\hline Imbert 2018 & EORTC/MSG criteria & 0.5 & 32 & Cohort & $\begin{array}{l}\text { Adults with } \\
\text { MTHF }\end{array}$ & 59.0 & 65.7 \\
\hline Hoenigl 2018 & EORTC/MSG criteria & NA & 28 & Cohort & $\begin{array}{l}\text { Adults with } \\
\text { MTHF }\end{array}$ & 60.0 & 28.6 \\
\hline Castillo 2018 & EORTC/MSG criteria & 0.5 & 106 & Cohort & $\begin{array}{l}\text { Adults with } \\
\text { MTHF }\end{array}$ & 55.3 & 65.1 \\
\hline Deng 2018 & EORTC/MSG criteria & 1.5 & 172 & Cohort & $\begin{array}{l}\text { Adults with } \\
\text { MTHF }\end{array}$ & NA & 70.2 \\
\hline Gupta 2017 & EORTC/MSG criteria & 1 & 71 & $\begin{array}{c}\text { Case } \\
\text { control }\end{array}$ & Adults with HM & 38.6 & 54.8 \\
\hline Eigl 2017 & EORTC/MSG criteria & 1 & 53 & Cohort & $\begin{array}{l}\text { Adults with } \\
\text { MTHF }\end{array}$ & 58.0 & 32.1 \\
\hline $\begin{array}{l}\text { Taghizadeh } \\
2017\end{array}$ & EORTC/MSG criteria & 0.5 & 116 & Cohort & $\begin{array}{c}\text { Adults with } \\
\text { MTHF }\end{array}$ & 46.0 & 62.9 \\
\hline Zhuang 2017 & EORTC/MSG criteria & 0.76 & 183 & Cohort & $\begin{array}{c}\text { Nonneutropenic } \\
\text { adults }\end{array}$ & NA & 55.7 \\
\hline Zhou 2017 & EORTC/MSG criteria & 0.7 & 120 & Cohort & $\begin{array}{c}\text { Nonneutropenic } \\
\text { people }\end{array}$ & NA & 53.3 \\
\hline Boch 2017 & EORTC/MSG criteria & 0.5 & 44 & Cohort & $\begin{array}{l}\text { Adults with } \\
\text { MTHF }\end{array}$ & NA & 52.3 \\
\hline Zhang 2016 & EORTC/MSG criteria & 0.5 & 94 & Cohort & $\begin{array}{l}\text { Adults with } \\
\text { MTHF }\end{array}$ & NA & NA \\
\hline Boch 2016 & EORTC/MSG criteria & 0.5 & 34 & Cohort & $\begin{array}{l}\text { Adults with } \\
\text { MTHF }\end{array}$ & $\begin{array}{c}\text { Proven/probable: } \\
\text { 57; no IPA: } 63\end{array}$ & 53.0 \\
\hline Fortun 2016 & EORTC/MSG criteria & 1 & 44 & Cohort & $\begin{array}{l}\text { Adults with } \\
\text { ISC/COPD }\end{array}$ & NA & 64.4 \\
\hline Lahmer 2016 & EORTC/MSG criteria & 0.5 & 49 & Cohort & $\begin{array}{l}\text { Adults with } \\
\text { MTHF }\end{array}$ & 59.0 & 57.0 \\
\hline Lin 2016 & EORTC/MSG criteria & 1 & 96 & Cohort & $\begin{array}{l}\text { Adults with } \\
\text { MTHF }\end{array}$ & 64.0 & 64.8 \\
\hline Ozger 2015 & EORTC/MSG criteria & $\mathrm{NA}$ & 44 & Cohort & $\begin{array}{c}\text { Nonneutropenic } \\
\text { adults }\end{array}$ & NA & 70.5 \\
\hline $\begin{array}{l}\text { Khodavaisy } \\
2015\end{array}$ & EORTC/MSG criteria & 1 & 43 & Cohort & $\begin{array}{l}\text { Adults with } \\
\text { MTHF }\end{array}$ & 56.5 & 58.8 \\
\hline $\begin{array}{l}\text { Mohammadi } \\
2015\end{array}$ & EORTC/MSG criteria & 0.5 & 70 & $\begin{array}{c}\text { Case } \\
\text { control }\end{array}$ & $\begin{array}{l}\text { Children with } \\
\text { MTHF }\end{array}$ & 8.4 & 62.5 \\
\hline Zhang 2015 & EORTC/MSG criteria & 1.19 & 121 & Cohort & $\begin{array}{l}\text { Adults with } \\
\text { MTHF }\end{array}$ & 59.3 & 51.2 \\
\hline Willinger 2014 & EORTC/MSG criteria & 1 & 47 & Cohort & Patients with TR & 50.6 & 63.6 \\
\hline
\end{tabular}


TABle 1: Continued.

\begin{tabular}{|c|c|c|c|c|c|c|c|}
\hline Study & Diagnostic standard & $\begin{array}{l}\text { Best } \\
\text { cutoffs }\end{array}$ & $\begin{array}{l}\text { Sample } \\
\text { size }\end{array}$ & $\begin{array}{l}\text { Study } \\
\text { design }\end{array}$ & $\begin{array}{c}\text { Patient } \\
\text { population }\end{array}$ & Mean age & $\begin{array}{c}\text { Male } \\
(\%)\end{array}$ \\
\hline Heng 2014 & EORTC/MSG criteria & 0.8 & 116 & Cohort & Adults with HM & $\begin{array}{l}\text { Proven/probable: } \\
\text { 54; no IFD: } 59\end{array}$ & 71.7 \\
\hline Affolter 2014 & EORTC/MSG criteria & 0.5 & 569 & Cohort & $\begin{array}{l}\text { Adults with } \\
\text { IC/respiratory } \\
\text { symptoms }\end{array}$ & 54.0 & 66.6 \\
\hline Prattes 2014 & EORTC/MSG criteria & 1 & 221 & Cohort & $\begin{array}{l}\text { Adults with } \\
\text { respiratory } \\
\text { disease }\end{array}$ & NA & 58.0 \\
\hline Hoenigl 2014 & EORTC/MSG criteria & 0.5 & 78 & $\begin{array}{c}\text { Case } \\
\text { control }\end{array}$ & $\begin{array}{l}\text { Adults with } \\
\text { MTHF }\end{array}$ & 58.0 & 67.0 \\
\hline Rose 2014 & EORTC/MSG criteria & 0.5 & 119 & Cohort & $\begin{array}{l}\text { Adults with } \\
\text { MTHF }\end{array}$ & NA & 54.5 \\
\hline de Mol 2013 & EORTC/MSG criteria & 0.5 & 41 & Cohort & $\begin{array}{l}\text { Children with } \\
\text { MTHF }\end{array}$ & 9.8 & 57.4 \\
\hline Kono 2013 & NA & 0.5 & 45 & Cohort & $\begin{array}{l}\text { Adults with } \\
\text { MTHF }\end{array}$ & NA & NA \\
\hline Zhang 2013 & EORTC/MSG criteria & 0.5 & 91 & Cohort & $\begin{array}{l}\text { Adults with } \\
\text { COPD }\end{array}$ & 64.2 & 80.2 \\
\hline Brownback 2013 & EORTC/MSG criteria & 0.5 & 143 & Cohort & Adults with IC & 50.4 & 75.0 \\
\hline Zhao 2013 & EORTC/MSG criteria & 0.5 & 112 & Cohort & $\begin{array}{l}\text { Patients with } \\
\text { MTHF }\end{array}$ & NA & NA \\
\hline Hadrich 2012 & EORTC/MSG criteria & 0.5 & 70 & $\begin{array}{l}\text { Case } \\
\text { control }\end{array}$ & $\begin{array}{c}\text { Patients with } \\
\text { HM }\end{array}$ & 37.6 & 0.7 \\
\hline Izumikawa 2012 & $\begin{array}{l}\text { Proposed enrollment criteria for } \\
\text { prospective clinical studies of CPA } \\
\text { by Denning were also employed, } \\
\text { with minor modifications, in this } \\
\text { investigation [79] }\end{array}$ & 0.4 & 144 & Cohort & $\begin{array}{l}\text { Adults with } \\
\text { MTHF }\end{array}$ & 64.8 & 61.8 \\
\hline Reinwald 2012 & EORTC/MSG criteria & 0.5 & 87 & Cohort & $\begin{array}{l}\text { Patients with } \\
\text { HM }\end{array}$ & NA & 0.7 \\
\hline Tabarsi 2012 & $\begin{array}{l}\text { Infectious Diseases Society of } \\
\text { America guidelines }\end{array}$ & 0.5 & 17 & Cohort & Patients with TR & 34.6 & NA \\
\hline D’Haese 2012 & EORTC/MSG criteria & 0.8 & 251 & $\begin{array}{l}\text { Case } \\
\text { control }\end{array}$ & $\begin{array}{l}\text { Patients with } \\
\text { MTHF }\end{array}$ & NA & 58.2 \\
\hline He 2012 & $\begin{array}{l}\text { Based on the case definition } \\
\text { proposed by Bulpa et al. [80] }\end{array}$ & 0.8 & 34 & Cohort & $\begin{array}{l}\text { Patients with } \\
\text { COPD }\end{array}$ & NA & NA \\
\hline Bhella 2012 & EORTC/MSG criteria & NA & 46 & Cohort & $\begin{array}{l}\text { Patients with } \\
\text { HM }\end{array}$ & NA & NA \\
\hline Zhang 2011 & EORTC/MSG criteria & 0.5 & 76 & Cohort & $\begin{array}{c}\text { Elderly patients } \\
\text { with lung } \\
\text { diseases }\end{array}$ & NA & NA \\
\hline Racil 2011 & EORTC/MSG criteria & 0.5 & 255 & Cohort & Adults with HM & 54.0 & 65.7 \\
\hline Torelli 2011 & EORTC/MSG criteria & 1 & 158 & Cohort & $\begin{array}{l}\text { Patients with } \\
\text { MTHF }\end{array}$ & NA & NA \\
\hline Acosta 2011 & EORTC/MSG criteria & 0.5 & 52 & Cohort & $\begin{array}{l}\text { Adults with } \\
\text { MTHF }\end{array}$ & 57.5 & 60.0 \\
\hline Luong 2011 & EORTC/MSG criteria & 0.5 & 150 & Cohort & Patients with TR & 58.4 & 51.3 \\
\hline Bergeron 2010 & EORTC/MSG criteria & 0.5 & 101 & Cohort & Adults with HM & 45.0 & 62.4 \\
\hline Hsu 2010 & EORTC/MSG criteria & 1.1 & 62 & $\begin{array}{l}\text { Case } \\
\text { control }\end{array}$ & $\begin{array}{l}\text { Patients with } \\
\text { hematology }\end{array}$ & NA & 72.6 \\
\hline $\begin{array}{l}\text { Pasqualotto } \\
2010\end{array}$ & EORTC/MSG criteria & 1.5 & 60 & Cohort & Patients with TR & 55.0 & 51.7 \\
\hline
\end{tabular}


TABLe 1: Continued.

\begin{tabular}{|c|c|c|c|c|c|c|c|}
\hline Study & Diagnostic standard & $\begin{array}{l}\text { Best } \\
\text { cutoffs }\end{array}$ & $\begin{array}{l}\text { Sample } \\
\text { size }\end{array}$ & $\begin{array}{l}\text { Study } \\
\text { design }\end{array}$ & $\begin{array}{c}\text { Patient } \\
\text { population }\end{array}$ & Mean age & $\begin{array}{c}\text { Male } \\
(\%)\end{array}$ \\
\hline Park 2010 & EORTC/MSG criteria & 0.5 & 359 & Cohort & $\begin{array}{c}\text { Adults with } \\
\text { MTHF }\end{array}$ & 57.8 & 62.1 \\
\hline Luong 2010 & EORTC/MSG criteria & 3 & 145 & Cohort & $\begin{array}{c}\text { Adults with } \\
\text { MTHF }\end{array}$ & 55.0 & 65.0 \\
\hline $\begin{array}{l}\text { Sarrafzadeh } \\
2010\end{array}$ & EORTC/MSG criteria & 1.5 & 49 & Cohort & $\begin{array}{l}\text { Adults with } \\
\text { MTHF }\end{array}$ & NA & $63.3^{*}$ \\
\hline Desai 2009 & EORTC/MSG criteria & 0.98 & 85 & Cohort & $\begin{array}{c}\text { Children with } \\
\text { HM/IC }\end{array}$ & 10.3 & 45.0 \\
\hline Fréalle 2009 & EORTC/MSG criteria & 1 & 64 & Cohort & Adults with HM & 49.2 & 71.9 \\
\hline Kimura 2009 & EORTC/MSG criteria & $\begin{array}{c}0.5- \\
1.3\end{array}$ & 26 & Cohort & Adults with HM & 70.0 & 80.4 \\
\hline Maertens 2009 & EORTC/MSG criteria & 1 & 99 & Cohort & Adults with HM & 53.6 & NA \\
\hline Shahid 2008 & EORTC/MSG criteria & NA & 59 & Cohort & Adults with $\mathrm{BC}$ & 58.0 & 91.3 \\
\hline $\begin{array}{l}\text { Meersseman } \\
2008\end{array}$ & EORTC/MSG criteria & 0.5 & 110 & Cohort & $\begin{array}{l}\text { Adults with } \\
\text { MTHF }\end{array}$ & 60.0 & 67.3 \\
\hline Clancy 2007 & EORTC/MSG criteria & 2.1 & 81 & Cohort & Patients with TR & 54.0 & 74.1 \\
\hline Husain 2007 & EORTC/MSG criteria & 0.5 & 117 & Cohort & Adults with TR & 52.3 & 44.0 \\
\hline Musher 2004 & EORTC/MSG criteria & 1 & 99 & Cohort & $\begin{array}{l}\text { Patients with } \\
\text { allogeneic HSCT }\end{array}$ & $\begin{array}{l}\text { Cases: } 45.2 ; \\
\text { controls: } 41.2\end{array}$ & NA \\
\hline Becker 2003 & EORTC/MSG criteria & 1 & 27 & Cohort & $\begin{array}{c}\text { Hematology } \\
\text { patients }\end{array}$ & NA & NA \\
\hline $\begin{array}{l}\text { Danpornprasert } \\
2010\end{array}$ & EORTC/MSG criteria & 0.5 & 30 & Cohort & $\begin{array}{l}\text { Patients with } \\
\text { MTHF }\end{array}$ & 41.0 & 56.7 \\
\hline
\end{tabular}

EORTC/MSG = European Organization for Research and Treatment of Cancer/Mycoses Study Group; BALF-GM= BALF-galactomannan; IA = invasive aspergillosis; $\mathrm{MTHF}=$ multiple host factors; $\mathrm{HM}=$ hematologic malignancy; $\mathrm{IC}=$ immunocompromised; $\mathrm{TR}=$ transplant recipients; $\mathrm{ISC}=$ immunosuppressive conditions; $\mathrm{COPD}=$ chronic obstructive pulmonary disease; $\mathrm{BC}=$ bronchogenic carcinoma; ${ }^{*}$ mean value in proven + probable + possible patients.

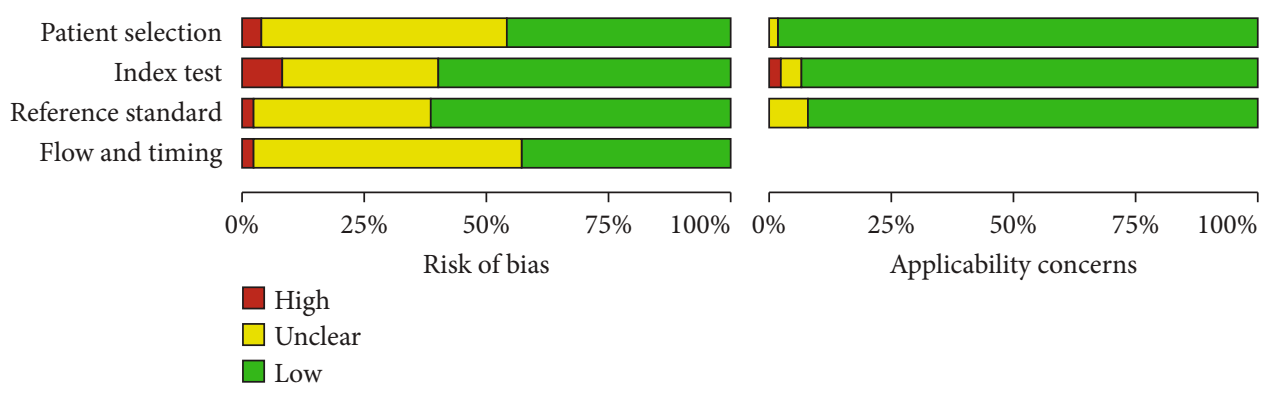

FIGURE 1: Overall quality assessment of all 65 included studies. Data are presented as stacked bars for each quality item, including modified quality assessment for studies of diagnostic accuracy (QUADAS) criteria.

included in 15 studies, in which 13 had cutoff values between 0.5 and 1.0, and the remaining two had cutoff values of 2.1 and 3, respectively. The SPE and SEN and associated 95\% CIs were 0.87 (0.85-0.98) and 0.81 (0.76-0.84), respectively. The PLR and NLR and associated 95\% CIs were $0.20(0.14-$ 0.29 ) and 9.78 (5.78-16.56), respectively. DOR was 72.29 (32.27-161.97). In addition to this, all measured $I^{2}$ values were $>50 \%$, and this indicated significant heterogeneity among the indicators of these studies. Figure 2 displays the SROC curves, in which they represent the relationship between SPE and SEN across the studies. The area under the SROC curve was 0.94, which indicated that the BALFGM has a high diagnostic ability.
3.4. Analyses for Proven+Probable+Possible vs. No IA. The analyses of proven+probable+possible vs. no IA were included in 7 studies, in which 6 of them had a threshold of 0.5 and one had a threshold of 1.0. The SPE and SEN and associated 95\% CIs were $0.82(0.79-0.95)$ and $0.59(0.55-$ $0.63)$, respectively. The PLR and NLR were 3.60 (95\% CI, 2.07-6.25) and 0.31 (95\% CI, 0.15-0.61), respectively. DOR was 14.04 (4.02-49.09).

Figure 2 shows the SROC curve, which represents the relationship between SPE and SEN throughout the study. The area under the SROC curve (AUC) was 0.86, which indicated that the resolution of BALF-GM analysis was not very high. 


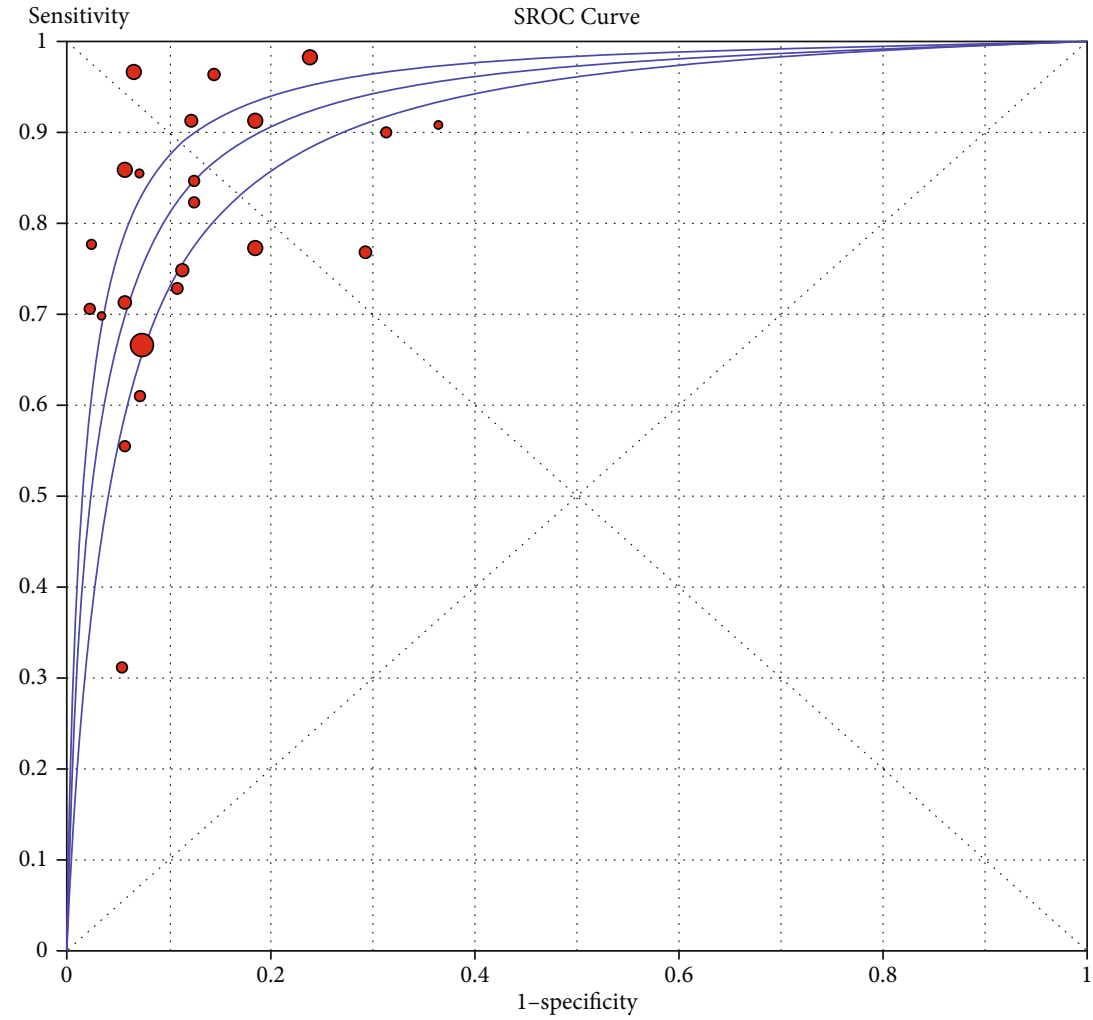

Symmetric SROC AUC $=0.9276$

$\mathrm{SE}(\mathrm{AUC})=0.0114$

$Q^{*}=0.8622$

$\mathrm{SE}\left(Q^{*}\right)=0.0136$

(a)

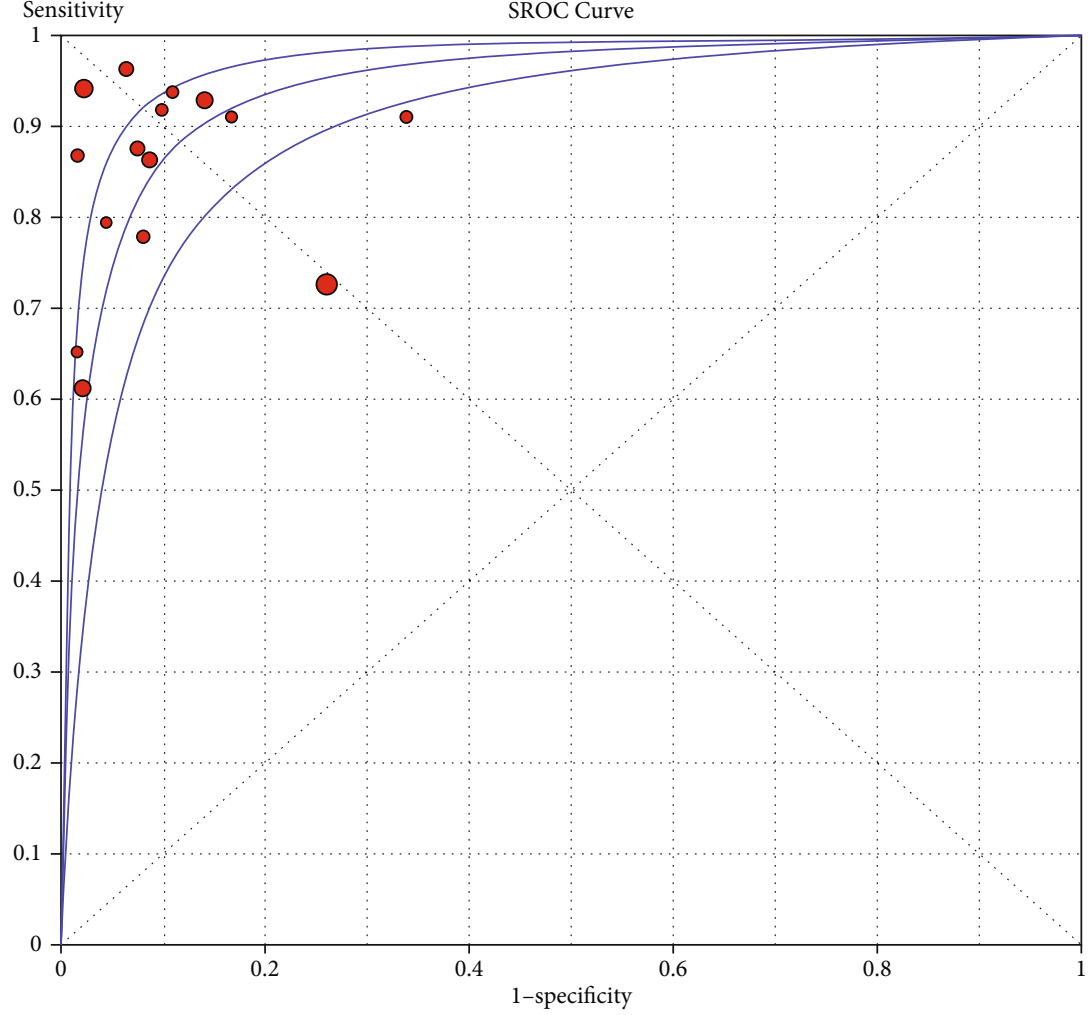

Symmetric SROC

AUC $=0.9444$

$\mathrm{SE}(\mathrm{AUC})=0.0155$

$Q^{*}=0.8831$

$\mathrm{SE}\left(Q^{*}\right)=0.0201$

(b)

Figure 2: Continued. 


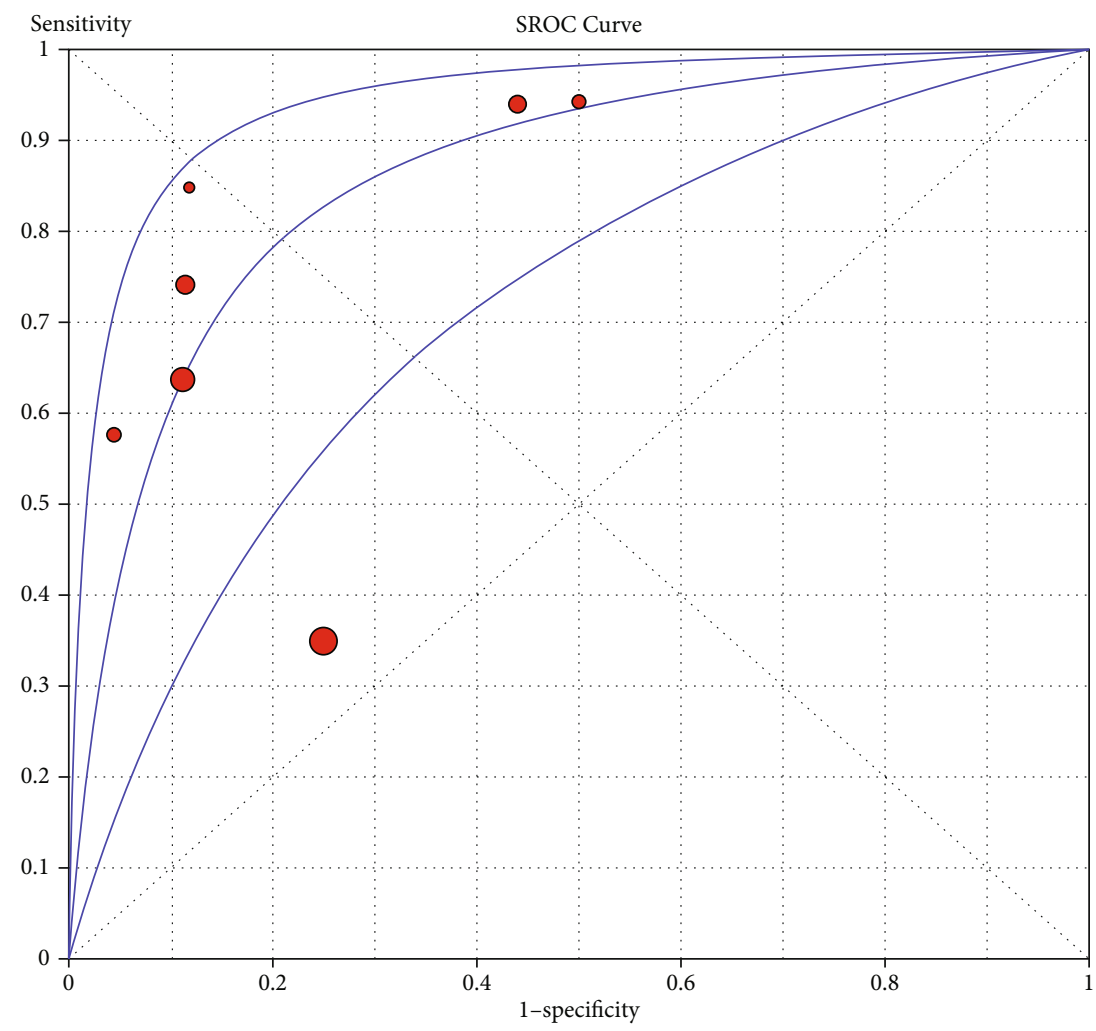

Symmetric SROC

AUC $=0.8587$

$\mathrm{SE}(\mathrm{AUC})=0.0441$

$Q^{*}=0.7895$

$\operatorname{SE}\left(Q^{*}\right)=0.0425$

(c)

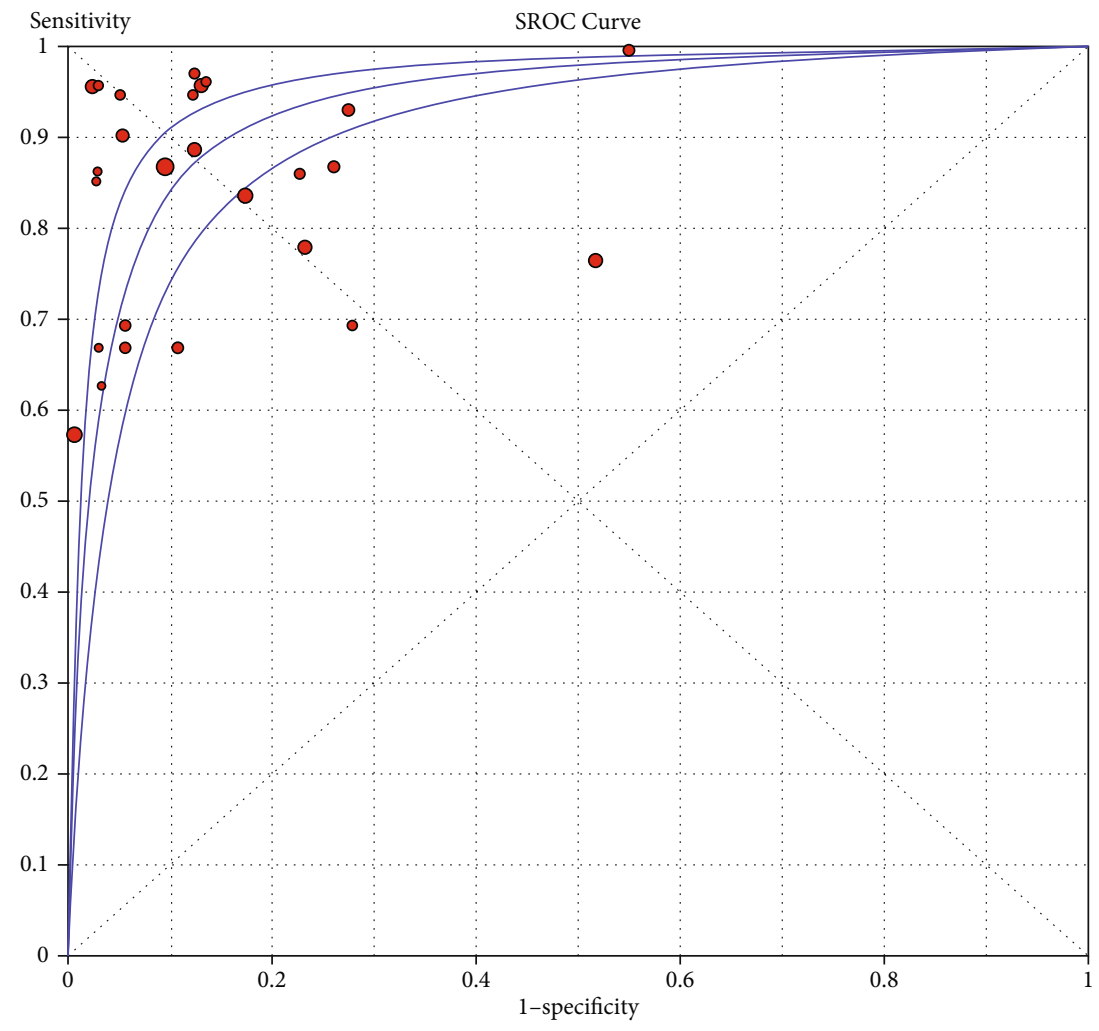

Symmetric SROC

AUC $=0.9368$

$\mathrm{SE}(\mathrm{AUC})=0.0135$

$Q^{*}=0.8735$

$\mathrm{SE}\left(\mathrm{Q}^{*}\right)=0.0168$

(d)

Figure 2: SROC curves from the bivariate model for (a) proven+probable vs. no IA, (b) proven+probable vs. possible+no IA, (c) proven+probable+possible vs. no IA, and (d) other, respectively. The smaller region (confidence contour) contains likely combinations of the mean value of sensitivity and specificity. The wider region (prediction contour) demonstrates more uncertainty as to where the likely values of sensitivity and specificity might occur for individual studies. SROC $=$ summary receiver operating characteristic. 
TABLE 2: Pooled sensitivity and specificity of the included studies for proven or probable vs. no IA.

\begin{tabular}{|c|c|c|}
\hline Study & Pooled SEN (95\% CI) & Pooled SPE (95\% CI) \\
\hline Cutoff of $0.5-1.0$ & $0.80(0.75-0.84)$ & $0.88(0.87-0.90)$ \\
\hline $\begin{array}{l}\text { Cutoff of greater } \\
\text { than } 1.0\end{array}$ & $0.84(0.79-0.89)$ & $0.88(0.85-0.90)$ \\
\hline
\end{tabular}

SEN = sensitivity; SPE $=$ specificity.

3.5. Analyses for Others. The analyses of others were included in 27 studies, in which 12 had cutoff values of 0.5 to 1,9 had cutoff values that are greater than 1.0, one had a cutoff value of 0.4 , and the remaining 4 could not be extracted. The SEN and SPE and associated 95\% CIs were 0.89 (0.86-0.91) and 0.85 (0.83-0.87), respectively. The NLR and PLR were 0.18 (95\% CI, 0.13-0.26) and 6.91 (95\% CI, 4.67-10.22), respectively. DOR was 49.41 (27.46-88.91).

Figure 2 displays the SROC curves, and the results showed significant heterogeneity. Funnel plot results revealed no significant publication bias.

3.6. Publication Bias. As shown in the funnel plot, the publication bias was not significant in "proven+probable vs. no IA" and "other" groups, with $p$ values of 0.43 and 0.69 , respectively. The remaining studies showed significant publication bias. The results are shown in Figure S4.

\section{Discussion}

Invasive fungal infections are particularly a significant cause of morbidity and death in immunocompromised patients [2], and so the diagnosis of IA remains to be crucial. Currently, the invasive procedures mostly rely on histopathological or cytopathological evidences, which are considered the gold standard for diagnosing IA [81]. However, this diagnostic method is rarely used in certain situations, such as in critically ill patients or patients with thrombocytopenia. Due to the difficulty in diagnosing IA, a number of approaches have been developed to overcome this problem. Since 2003, there were several studies that explored the accuracy of the BALF-GM test in diagnosing IA. In 2010, Guo et al. [82] have analyzed cases with proven+probable IA vs. possible+no IA by conducting a meta-analysis, and the results achieved high accuracy of $>90 \%$ for both SPE and SEN. Compared with the SEN and SPE as summarized in Guo et al.'s research, our study yielded lower SEN 0.81 (0.76-0.84) and SPE 0.87 (0.85-0.89). Four articles we included were different from Guo et al. This may be the reason for the difference. Studies showed that PLR greater than 10 and NLR less than 0.1 provided compelling diagnostic evidence, while the PLR greater than 5 and NLR less than 0.2 also provided a strong diagnostic basis to diagnose, respectively, in most of the cases [83, 84]. Although our analysis results are not so good compared with Guo et al., it still provides a strong basis for diagnosis. Similarly, the study conducted by Zou et al. showed similar results, with a PLR less than 10 but greater than 5 and an NLR of 0.15 [10]. In addition to SPE, SEN, NLR, AUC, and PLR, another test performance DOR was also reported in our study. DOR not only combines the advantages of SPE and SEN but also has superior accuracy as a single indicator [85]. The DOR was 32.27-161.97, which remained high. Based on the abovementioned results, our study also showed high accuracy for possible or no IA cases.

In the above four groups, the "proven+probable vs. no IA" group, "proven+probable vs. possible+no IA" group, "proven+probable+possible vs. no IA" group, and "others" group, the "proven or probable vs. no IA" has been implemented in many studies, which may suggest a good clinical significance. In our study, the "proven+probable vs. no IA" group showed the best SEN of 0.88 (0.87-0.90). In contrast, the "proven+probable+possible vs. no IA" group showed the lowest SPE of $0.82(0.79-0.85)$, the lowest SPE of 0.82 (0.79-0.85), and the lowest AUC of 0.86. The 2019 EORTC/MSG criteria also indicated that the probable and possible categories are applicable only to immunodeficient patients [86]. In summary, this group was not so rational. Therefore, we do not recommend such grouping for patients without immunodeficiency. However, a study found that the cause of immunosuppression is not related to the EORTC/MSG classification. This study found that the classification according to the definition of EORTC/MSG criteria revealed no significant association with the cause of immunosuppression but showed a trend towards better application in stem cell transplant cases [81]. Further research needs to be done.

As shown in Table 2, in the "proven+possible vs. no IA" group, aggregated performance indicators are provided at different thresholds. However, when studies with cutoff values greater than 1 were included, the highest SEN value for BALF-GM was only 0.86 . The differences in the results between the whole analysis and the subgroup analysis were mainly due to the number of studies included. When using a threshold range from 0.5 to $1.0,15$ studies were included, but when a threshold range of greater than 1 was used, only 7 studies were included. If a cutoff value of greater than 1 was used in all these studies, false-negative values might be lower or remained the same, resulting in increased or retained SEN value. Therefore, using the cutoff value of greater than 1 will have a better result.

One possible cause of heterogeneity is the use of different thresholds in different studies. The cutoff value used in this study was $0.5-1.0$, and the heterogeneity was significantly reduced.

\section{Conclusions}

The BALF-GM assay is considered a method for diagnosing IA with high SEN and SPE, and if a cutoff value of greater than 1 was used, false-negative values might be lower or remained the same, resulting in increased or retained SEN value. Therefore, we recommend using the BALF-GM test to diagnose IA. Using the cutoff value of greater than 1 will have a better result.

\section{Data Availability}

There are no available data. 


\section{Conflicts of Interest}

The authors declare that there are no competing interests associated with the manuscript.

\section{Authors' Contributions}

$\mathrm{Xu}-$ Guang Guo conceived and designed the experiments. Xun-Jie Cao, Ya-Ping Li, and Li-Min Xie analyzed the data and made the tables. Hong-Lang Zhang and Yu-Shan Qin contributed to the production of figures by the analysis tools. Xun-Jie Cao, Ya-Ping Li, and Li-Min Xie participated in the writing, reading, and revising of the manuscript and approved the final version of the manuscript. Xun-Jie Cao and Ya-Ping Li contributed equally to this work.

\section{Acknowledgments}

This study was supported by Guangzhou Medical University (No. 2019A020).

\section{Supplementary Materials}

Figure S1: flow diagram of inclusion and exclusion studies. Figure S2: subgroup analysis for proven+probable vs. no (sensitivity). Figure S3: subgroup analysis for proven+probable vs. no (specificity). Figure S4: funnel plot that can reveal the publication bias of these four groups. (Supplementary Materials)

\section{References}

[1] R. Garcia-Rubio, M. Cuenca-Estrella, and E. Mellado, "Triazole resistance in Aspergillus species: an emerging problem," Drugs, vol. 77, no. 6, pp. 599-613, 2017.

[2] K. J. Kwon-Chung and J. A. Sugui, "Aspergillus fumigatuswhat makes the species a ubiquitous human fungal pathogen?," PLoS Pathogens, vol. 9, no. 12, article e1003743, 2013.

[3] M. Morgand, B. Rammaert, S. Poirée et al., "Chronic invasive Aspergillus sinusitis and otitis with meningeal extension successfully treated with voriconazole," Antimicrobial Agents and Chemotherapy, vol. 59, no. 12, pp. 7857-7861, 2015.

[4] M. H. Miceli and C. A. Kauffman, "Aspergillus galactomannan for diagnosing invasive aspergillosis," JAMA, vol. 318, no. 12, pp. 1175-1176, 2017.

[5] T. F. Patterson and J. P. Donnelly, "New concepts in diagnostics for invasive mycoses: non-culture-based methodologies," Journal of Fungi, vol. 5, no. 1, p. 9, 2019.

[6] S. Schelenz, R. A. Barnes, R. C. Barton et al., "British Society for Medical Mycology best practice recommendations for the diagnosis of serious fungal diseases," The Lancet Infectious Diseases, vol. 15, no. 4, pp. 461-474, 2015.

[7] A. J. Ullmann, J. M. Aguado, S. Arikan-Akdagli et al., "Diagnosis and management of Aspergillus diseases: executive summary of the 2017 ESCMID-ECMM-ERS guideline," Clinical microbiology and infection: the official publication of the European Society of Clinical Microbiology and Infectious Diseases, vol. 24, Suppl 1, pp. e1-e38, 2018.

[8] K. de Heer, M. G. Gerritsen, C. E. Visser, and M. M. G. Leeflang, "Galactomannan detection in broncho-alveolar lavage fluid for invasive aspergillosis in immunocompromised patients," The Cochrane Database of Systematic Reviews, vol. 5, no. 5, article CD012399, 2019.

[9] T. F. Patterson, G. R. Thompson III, D. W. Denning et al., "Practice guidelines for the diagnosis and management of aspergillosis: 2016 update by the Infectious Diseases Society of America," Clinical infectious diseases: an official publication of the Infectious Diseases Society of America, vol. 63, no. 4, pp. e1-e60, 2016.

[10] M. Zou, L. Tang, S. Zhao et al., "Systematic review and metaanalysis of detecting galactomannan in bronchoalveolar lavage fluid for diagnosing invasive aspergillosis," PLoS One, vol. 7, no. 8, article e43347, 2012.

[11] B. De Pauw, T. J. Walsh, J. P. Donnelly et al., "Revised definitions of invasive fungal disease from the European Organization for Research and Treatment of Cancer/Invasive Fungal Infections Cooperative Group and the National Institute of Allergy and Infectious Diseases Mycoses Study Group (EORTC/MSG) Consensus Group," Clinical Infectious Diseases, vol. 46, no. 12, pp. 1813-1821, 2008.

[12] Y. L. Guo, Y. Q. Chen, K. Wang, S. M. Qin, C. Wu, and J. L. Kong, "Accuracy of BAL galactomannan in diagnosing invasive aspergillosis: a bivariate metaanalysis and systematic review," Chest, vol. 138, no. 4, pp. 817-824, 2010.

[13] J. J. Deeks, P. Macaskill, and L. Irwig, "The performance of tests of publication bias and other sample size effects in systematic reviews of diagnostic test accuracy was assessed," Journal of Clinical Epidemiology, vol. 58, no. 9, pp. 882893, 2005.

[14] L. Liu, J. Li, H. Dong et al., "Diagnostic value of the combinations of bronchoalveolar lavage fluid galactomannan test and serum galactomannan test in invasive pulmonary aspergillosis," Zhonghua wei zhong bing ji jiu yi xue, vol. 31, no. 3, pp. 331-335, 2019.

[15] J. D. Jenks, S. R. Mehta, R. Taplitz, S. Aslam, S. L. Reed, and M. Hoenigl, "Point-of-care diagnosis of invasive aspergillosis in non-neutropenic patients: Aspergillus galactomannan lateral flow assay versus Aspergillus-specific lateral flow device test in bronchoalveolar lavage," Mycoses, vol. 62, no. 3, pp. 230-236, 2019.

[16] A. Rozaliyani, R. Sedono, A. Jusuf et al., "A novel diagnosis scoring model to predict invasive pulmonary aspergillosis in the intensive care unit," Saudi Medical Journal, vol. 40, no. 2, pp. 140-146, 2019.

[17] Y. Yu, C. Zhu, H. Shen et al., "Galactomannan detection in bronchoalveolar lavage fluid corrected by urea dilution for the diagnosis of invasive pulmonary aspergillosis among nonneutropenic patients," Journal of Thoracic Disease, vol. 11, no. 2, pp. 465-476, 2019.

[18] I. S. Sehgal, S. Dhooria, H. Choudhary et al., "Efficiency of A fumigatus-specific IgG and galactomannan testing in the diagnosis of simple aspergilloma," Mycoses, vol. 62, no. 12, pp. 1108-1115, 2019.

[19] A.-P. Bellanger, H. Gbaguidi-Haore, N. Tatoyan, A. Berceanu, E. Scherer, and L. Millon, "Local retrospective analysis of galactomannan cut-off values in bronchoalveolar lavage fluids for diagnosis of invasive aspergillosis," Folia Microbiologica, vol. 63, no. 6, pp. 757-761, 2018.

[20] S. Imbert, I. Meyer, M. Palous et al., "Aspergillus PCR in bronchoalveolar lavage fluid for the diagnosis and prognosis of aspergillosis in patients with hematological and nonhematological conditions," Frontiers in Microbiology, vol. 9, 2018. 
[21] M. Hoenigl, S. Eigl, S. Heldt, W. Duettmann, C. Thornton, and J. Prattes, "Clinical evaluation of the newly formatted lateralflow device for invasive pulmonary aspergillosis," Mycoses, vol. 61, no. 1, pp. 40-43, 2018.

[22] C. G. Castillo, C. A. Kauffman, J. Zhai, H. Jiang, S. M. Agozino, and M. H. Miceli, "Testing the performance of a prototype lateral flow device using bronchoalveolar lavage fluid for the diagnosis of invasive pulmonary aspergillosis in high-risk patients," Mycoses, vol. 61, no. 1, pp. 4-10, 2018.

[23] J. Deng, S. Y. Wu, Y. Liu et al., "Galactomannan tests of bronchoalveolar lavage fluid for diagnosing invasive pulmonary aspergillosis," Sichuan da xue xue bao. Yi Xue Ban Journal of Sichuan University. Medical science edition, vol. 49, no. 1, pp. 124-128, 2018.

[24] A. Gupta, M. R. Capoor, T. Shende et al., "Comparative evaluation of galactomannan test with bronchoalveolar lavage and serum for the diagnosis of invasive aspergillosis in patients with hematological malignancies," Journal of laboratory physicians, vol. 9, no. 4, pp. 234-238, 2017.

[25] S. Eigl, M. Hoenigl, B. Spiess et al., "Galactomannan testing and Aspergillus PCR in same-day bronchoalveolar lavage and blood samples for diagnosis of invasive aspergillosis," Medical Mycology, vol. 55, no. 5, pp. 528-534, 2017.

[26] M. Taghizadeh-Armaki, M. T. Hedayati, V. Moqarabzadeh et al., "Effect of involved Aspergillus species on galactomannan in bronchoalveolar lavage of patients with invasive aspergillosis," Journal of Medical Microbiology, vol. 66, no. 7, pp. 898904, 2017.

[27] Q. Zhuang, H. Ma, Y. Zhang et al., "Galactomannan in bronchoalveolar lavage fluid for diagnosis of invasive pulmonary aspergillosis with nonneutropenic patients," Canadian Respiratory Journal, vol. 2017, Article ID 3685261, 7 pages, 2017.

[28] W. Zhou, H. Li, Y. Zhang et al., "Diagnostic value of galactomannan antigen test in serum and bronchoalveolar lavage fluid samples from patients with nonneutropenic invasive pulmonary aspergillosis," Journal of Clinical Microbiology, vol. 55, no. 7, pp. 2153-2161, 2017.

[29] T. Boch, M. Reinwald, B. Spiess et al., "Diagnostics of pulmonary aspergillosis in critically ill hematological and nonhematological patients in the intensive care unit by combined use of galactomannan, 1-3-beta-D-glucan, aspergillus specific PCR and conventional culture in concurrent blood and bronchoalveolar lavage samples - results of a multicenter prospective pilot study," Blood, vol. 130, 2017.

[30] P. C. Lin, Q. Q. Lai, Y. Zhou et al., "The diagnostic performance of galactomannan detection for invasive pulmonary aspergillosis in non-neutropenic hosts," Zhonghua jie he he hu xi za zhi = Zhonghua jiehe he huxi zazhi=Chinese journal of tuberculosis and respiratory diseases, vol. 39, no. 12, pp. 929933, 2016.

[31] S. Zhang, S. Wang, Z. Wan, C. Que, R. Li, and J. Yu, "Quantitative real-time PCR and Platelia galactomannan assay for the diagnosis of invasive pulmonary aspergillosis: bronchoalveolar lavage fluid performs better than serum in non-neutropaenic patients," Mycopathologia, vol. 181, no. 9-10, pp. 625-629, 2016.

[32] T. Boch, D. Buchheidt, B. Spiess, T. Miethke, W. K. Hofmann, and M. Reinwald, "Direct comparison of galactomannan performance in concurrent serum and bronchoalveolar lavage samples in immunocompromised patients at risk for invasive pulmonary aspergillosis," Mycoses, vol. 59, no. 2, pp. 80-85, 2016.
[33] J. Fortún, P. Martín-Dávila, E. G. G. de la Pedrosa et al., "Galactomannan in bronchoalveolar lavage fluid for diagnosis of invasive aspergillosis in non-hematological patients," Journal of Infection, vol. 72, no. 6, pp. 738-744, 2016.

[34] T. Lahmer, M. Neuenhahn, J. Held, S. Rasch, R. M. Schmid, and W. Huber, "Comparison of 1,3- $\beta$ - $\mathrm{d}$-glucan with galactomannan in serum and bronchoalveolar fluid for the detection of Aspergillus species in immunosuppressed mechanical ventilated critically ill patients," Journal of Critical Care, vol. 36, pp. 259-264, 2016.

[35] S. Khodavaisy, M. T. Hedayati, M. Alialy, M. R. Habibi, and H. Badali, "Detection of galactomannan in bronchoalveolar lavage of the intensive care unit patients at risk for invasive aspergillosis," Current Medical Mycology, vol. 1, no. 1, pp. 12-17, 2015.

[36] S. Mohammadi, S. Khalilzadeh, K. Goudarzipour et al., "Bronchoalveolar galactomannan in invasive pulmonary aspergillosis: a prospective study in pediatric patients," Medical Mycology, vol. 53, no. 7, pp. 709-716, 2015.

[37] S. Özger, K. Hizel, A. Kalkanci et al., "Evaluation of risk factors for invasive pulmonary aspergillosis and detection of diagnostic values of galactomannan and PCR methods in bronchoalveolar lavage samples from non-neutropenic intensive care unit patients," Mikrobiyoloji Bülteni, vol. 49, no. 4, pp. 565$575,2015$.

[38] S. Zhang, S. Wang, Z. Wan, R. Li, and J. Yu, "The diagnosis of invasive and noninvasive pulmonary aspergillosis by serum and bronchoalveolar lavage fluid galactomannan assay," BioMed Research International, vol. 2015, Article ID 943691, 5 pages, 2015.

[39] B. Willinger, M. Lackner, C. Lass-Flörl et al., "Bronchoalveolar lavage lateral-flow device test for invasive pulmonary aspergillosis in solid organ transplant patients: a semiprospective multicenter study," Transplantation, vol. 98, no. 8, pp. 898-902, 2014.

[40] S. C. Heng, S. C. A. Chen, C. O. Morrissey et al., "Clinical utility of Aspergillus galactomannan and PCR in bronchoalveolar lavage fluid for the diagnosis of invasive pulmonary aspergillosis in patients with haematological malignancies," Diagnostic Microbiology and Infectious Disease, vol. 79, no. 3, pp. 322$327,2014$.

[41] K. Affolter, M. Tamm, K. Jahn et al., "Galactomannan in bronchoalveolar lavage for diagnosing invasive fungal disease," American Journal of Respiratory and Critical Care Medicine, vol. 190, no. 3, pp. 309-317, 2014.

[42] J. Prattes, H. Flick, F. Prüller et al., "Novel tests for diagnosis of invasive aspergillosis in patients with underlying respiratory diseases," American Journal of Respiratory and Critical Care Medicine, vol. 190, no. 8, pp. 922-929, 2014.

[43] M. Hoenigl, J. Prattes, B. Spiess et al., "Performance of galactomannan, beta-d-glucan, Aspergillus lateral-flow device, conventional culture, and PCR tests with bronchoalveolar lavage fluid for diagnosis of invasive pulmonary aspergillosis," Journal of Clinical Microbiology, vol. 52, no. 6, pp. 2039-2045, 2014.

[44] S. R. Rose, S. Vallabhajosyula, M. G. Velez et al., "The utility of bronchoalveolar lavage beta-D-glucan testing for the diagnosis of invasive fungal infections," The Journal of Infection, vol. 69, no. 3, pp. 278-283, 2014.

[45] M. de Mol, J. C. de Jongste, M. van Westreenen et al., "Diagnosis of invasive pulmonary aspergillosis in children with bronchoalveolar lavage galactomannan," Pediatric Pulmonology, vol. 48, no. 8, pp. 789-796, 2013. 
[46] Y. Zhao, C. R. Stensvold, D. S. Perlin, and M. C. Arendrup, "Azole resistance in Aspergillus fumigatus from bronchoalveolar lavage fluid samples of patients with chronic diseases," The Journal of Antimicrobial Chemotherapy, vol. 68, no. 7, pp. 1497-1504, 2013.

[47] X.-B. Zhang, G.-P. Chen, Q.-C. Lin, X. Lin, H.-Y. Zhang, and J.-H. Wang, "Bronchoalveolar lavage fluid galactomannan detection for diagnosis of invasive pulmonary aspergillosis in chronic obstructive pulmonary disease," Medical Mycology, vol. 51, no. 7, pp. 688-695, 2013.

[48] Y. Kono, K. Tsushima, K. Yamaguchi et al., "The utility of galactomannan antigen in the bronchial washing and serum for diagnosing pulmonary aspergillosis," Respiratory Medicine, vol. 107, no. 7, pp. 1094-1100, 2013.

[49] K. R. Brownback, L. R. Pitts, and S. Q. Simpson, "Utility of galactomannan antigen detection in bronchoalveolar lavage fluid in immunocompromised patients," Mycoses, vol. 56, no. 5, pp. 552-558, 2013.

[50] K. Izumikawa, Y. Yamamoto, T. Mihara et al., "Bronchoalveolar lavage galactomannan for the diagnosis of chronic pulmonary aspergillosis," Medical Mycology, vol. 50, no. 8, pp. 811$817,2012$.

[51] M. Reinwald, B. Spiess, W. J. Heinz et al., "Diagnosing pulmonary aspergillosis in patients with hematological malignancies: a multicenter prospective evaluation of an Aspergillus PCR assay and a galactomannan ELISA in bronchoalveolar lavage samples," European Journal of Haematology, vol. 89, no. 2, pp. 120-127, 2012.

[52] P. Tabarsi, A. Soraghi, M. Marjani et al., "Comparison of serum and bronchoalveolar lavage galactomannan in diagnosing invasive aspergillosis in solid-organ transplant recipients," Experimental and Clinical Transplantation, vol. 10, no. 3, pp. 278-281, 2012.

[53] H. He, L. Ding, B. Sun, F. Li, and Q. Zhan, "Role of galactomannan determinations in bronchoalveolar lavage fluid samples from critically ill patients with chronic obstructive pulmonary disease for the diagnosis of invasive pulmonary aspergillosis: a prospective study," Critical Care, vol. 16, no. 4, p. R138, 2012.

[54] J. D'Haese, K. Theunissen, E. Vermeulen et al., "Detection of galactomannan in bronchoalveolar lavage fluid samples of patients at risk for invasive pulmonary aspergillosis: analytical and clinical validity," Journal of Clinical Microbiology, vol. 50, no. 4, pp. 1258-1263, 2012.

[55] S. Bhella, N. Paul, S. Husain, and J. M. Brandwein, "Comparison of sensitivity of low-dose CT scan and serum galactomannan in patients with hematologic malignancies and positive bronchoalveolar lavage for invasive pulmonary Aspergillosis," Blood, vol. 120, no. 21, p. 1490, 2012.

[56] Z. Racil, I. Kocmanova, M. Toskova et al., "Galactomannan detection in bronchoalveolar lavage fluid for the diagnosis of invasive aspergillosis in patients with hematological diseasesthe role of factors affecting assay performance," International Journal of Infectious Diseases, vol. 15, no. 12, pp. E874-E881, 2011.

[57] R. Torelli, M. Sanguinetti, A. Moody et al., "Diagnosis of invasive aspergillosis by a commercial real-time PCR assay for Aspergillus DNA in bronchoalveolar lavage fluid samples from high-risk patients compared to a galactomannan enzyme immunoassay," Journal of Clinical Microbiology, vol. 49, no. 12, pp. 4273-4278, 2011.

[58] X.-B. Zhang, Q.-C. Lin, X. Lin et al., "Galactomannan detection in bronchoalveolar lavage fluid facilitates the diagnosis of invasive pulmonary aspergillosis in elderly patients with lung diseases," Respirology, vol. 162, no. SI, pp. 56-56, 2011.

[59] J. Acosta, M. Catalan, A. del Palacio-Peréz-Medel et al., "A prospective comparison of galactomannan in bronchoalveolar lavage fluid for the diagnosis of pulmonary invasive aspergillosis in medical patients under intensive care: comparison with the diagnostic performance of galactomannan and of $(1 \rightarrow$ 3)- $\beta$-d-glucan chromogenic assay in serum samples," Clinical Microbiology and Infection, vol. 17, no. 7, pp. 1053-1060, 2011.

[60] I. Hadrich, C. Mary, F. Makni et al., "Comparison of PCRELISA and real-time PCR for invasive aspergillosis diagnosis in patients with hematological malignancies," Medical Mycology, vol. 49, no. 5, pp. 489-494, 2011.

[61] M.-L. Luong, C. J. Clancy, A. Vadnerkar et al., "Comparison of an Aspergillus real-time polymerase chain reaction assay with galactomannan testing of bronchoalvelolar lavage fluid for the diagnosis of invasive pulmonary aspergillosis in lung transplant recipients," Clinical Infectious Diseases, vol. 52, no. 10, pp. 1218-1226, 2011.

[62] A. Bergeron, A. Belle, A. Sulahian et al., "Contribution of galactomannan antigen detection in BAL to the diagnosis of invasive pulmonary aspergillosis in patients with hematologic malignancies," Chest, vol. 137, no. 2, pp. 410-415, 2010.

[63] L.-Y. Hsu, Y. Ding, J. Phua et al., "Galactomannan testing of bronchoalveolar lavage fluid is useful for diagnosis of invasive pulmonary aspergillosis in hematology patients," BMC Infectious Diseases, vol. 10, no. 1, 2010.

[64] A. C. Pasqualotto, M. O. Xavier, L. B. Sánchez et al., "Diagnosis of invasive aspergillosis in lung transplant recipients by detection of galactomannan in the bronchoalveolar lavage fluid," Transplantation, vol. 90, no. 3, pp. 306-311, 2010.

[65] S. Y. Park, S. O. Lee, S. H. Choi et al., “Aspergillus galactomannan antigen assay in bronchoalveolar lavage fluid for diagnosis of invasive pulmonary aspergillosis," Journal of Infection, vol. 61, no. 6, pp. 492-498, 2010.

[66] M.-L. Luong, C. Filion, A.-C. Labbé et al., "Clinical utility and prognostic value of bronchoalveolar lavage galactomannan in patients with hematologic malignancies," Diagnostic Microbiology and Infectious Disease, vol. 68, no. 2, pp. 132-139, 2010.

[67] S. A. Sarrafzadeh, R. A. Hoseinpoor, M. Ardalan, D. Mansouri, P. Tabarsi, and Z. Pourpak, "The accuracy of serum galactomannan assay in diagnosing invasive pulmonary aspergillosis," Iranian Journal of Allergy Asthma and Immunology, vol. 9, no. 3, pp. 149-155, 2010.

[68] P. Danpornprasert, S. Foongladda, and J. Tscheikuna, "Impact of bronchoalveolar lavage galactomannan on the outcome of patients at risk for invasive pulmonary aspergillosis," Journal of the Medical Association of Thailand = Chotmaihet thangphaet, vol. 93, Suppl 1, pp. S86-S93, 2010.

[69] J. Maertens, V. Maertens, K. Theunissen et al., "Bronchoalveolar lavage fluid galactomannan for the diagnosis of invasive pulmonary aspergillosis in patients with hematologic diseases," Clinical infectious diseases: an official publication of the Infectious Diseases Society of America, vol. 49, no. 11, pp. 1688-1693, 2009.

[70] R. Desai, L. A. Ross, and J. A. Hoffman, “The role of bronchoalveolar lavage galactomannan in the diagnosis of pediatric invasive aspergillosis," The Pediatric Infectious Disease Journal, vol. 28, no. 4, pp. 283-286, 2009.

[71] E. Fréalle, K. Decrucq, F. Botterel et al., "Diagnosis of invasive aspergillosis using bronchoalveolar lavage in haematology patients: influence of bronchoalveolar lavage human DNA 
content on real-time PCR performance," European journal of clinical microbiology \& infectious diseases: official publication of the European Society of Clinical Microbiology, vol. 28, no. 3, pp. 223-232, 2009.

[72] S. Kimura, J. Odawara, T. Aoki, M. Yamakura, M. Takeuchi, and K. Matsue, "Detection of sputum Aspergillus galactomannan for diagnosis of invasive pulmonary aspergillosis in haematological patients," International Journal of Hematology, vol. 90, no. 4, pp. 463-470, 2009.

[73] M. Shahid, A. Malik, and R. Bhargava, "Bronchogenic carcinoma and secondary aspergillosis-common yet unexplored: evaluation of the role of bronchoalveolar lavage-polymerase chain reaction and some nonvalidated serologic methods to establish early diagnosis," Cancer, vol. 113, no. 3, pp. 547558, 2008.

[74] W. Meersseman, K. Lagrou, J. Maertens et al., "Galactomannan in bronchoalveolar lavage fluid: a tool for diagnosing aspergillosis in intensive care unit patients," American Journal of Respiratory and Critical Care Medicine, vol. 177, no. 1, pp. 27-34, 2008.

[75] C. J. Clancy, R. A. Jaber, H. L. Leather et al., "Bronchoalveolar lavage galactomannan in diagnosis of invasive pulmonary aspergillosis among solid-organ transplant recipients," Journal of Clinical Microbiology, vol. 45, no. 6, pp. 1759-1765, 2007.

[76] S. Husain, D. L. Paterson, S. M. Studer et al., "Aspergillus galactomannan antigen in the bronchoalveolar lavage fluid for the diagnosis of invasive aspergillosis in lung transplant recipients," Transplantation, vol. 83, no. 10, pp. 1330-1336, 2007.

[77] B. Musher, D. Fredricks, W. Leisenring, S. A. Balajee, C. Smith, and K. A. Marr, "Aspergillus galactomannan enzyme immunoassay and quantitative PCR for diagnosis of invasive aspergillosis with bronchoalveolar lavage fluid," Journal of Clinical Microbiology, vol. 42, no. 12, pp. 5517-5522, 2004.

[78] M. J. Becker, E. J. Lugtenburg, J. J. Cornelissen, C. van der Schee, H. C. Hoogsteden, and S. de Marie, "Galactomannan detection in computerized tomography-based bronchoalveolar lavage fluid and serum in haematological patients at risk for invasive pulmonary aspergillosis," British Journal of Haematology, vol. 121, no. 3, pp. 448-457, 2003.

[79] D. W. Denning, K. Riniotis, R. Dobrashian, and H. Sambatakou, "Chronic cavitary and fibrosing pulmonary and pleural aspergillosis: case series, proposed nomenclature change, and review," Clinical Infectious Diseases, vol. 37, Suppl. 3, pp. S265-S280, 2003.

[80] P. Bulpa, A. Dive, and Y. Sibille, "Invasive pulmonary aspergillosis in patients with chronic obstructive pulmonary disease," The European Respiratory Journal, vol. 30, no. 4, pp. 782800, 2007.

[81] H. Rieger, D. Lustig, S. Barlow et al., "Applicability of the EORTC/MSG criteria for IFD in clinical practice," Annals of Hematology, vol. 94, no. 5, pp. 847-855, 2015.

[82] Y. L. Guo, Y. Q. Chen, K. Wang, S. M. Qin, C. Wu, and J. L. Kong, "Accuracy of BAL galactomannan in diagnosing invasive aspergillosis," Chest, vol. 138, no. 4, pp. 817-824, 2010.

[83] J. J. Deeks, "Systematic reviews in health care: systematic reviews of evaluations of diagnostic and screening tests," $B M J$, vol. 323, no. 7305, pp. 157-162, 2001.

[84] M. F. Drummond, "Users' Guides to the Medical Literature," JAMA, vol. 277, no. 19, pp. 1552-1557, 1997.
[85] A. S. Glas, J. G. Lijmer, M. H. Prins, G. J. Bonsel, and P. M. M. Bossuyt, "The diagnostic odds ratio: a single indicator of test performance," Journal of Clinical Epidemiology, vol. 56, no. 11, pp. 1129-1135, 2003.

[86] J. P. Donnelly et al., "Revision and update of the consensus definitions of invasive fungal disease from the European Organization for Research and Treatment of Cancer and the Mycoses Study Group Education and Research Consortium," Clinical Infectious Diseases, vol. 71, no. 6, pp. 1367-1376, 2019. 